\title{
Sustentabilidade e cadeia de suprimentos: uma perspectiva comparada de publicações nacionais e internacionais
}

\author{
Sylmara Lopes Francelino Gonçalves Dias ${ }^{\mathrm{a} *}$, Letícia Labegalini ${ }^{\mathrm{b}}$, João Mário Csillag $^{\mathrm{c}}$ \\ ${ }^{a *}$ sgdias@usp.br, EACH-USP, Brasil \\ blelabega@hotmail.com, FGV-EAESP, Brasil \\ cjoao.mario.csillag@fgv.br, FGV-EAESP, Brasil
}

\begin{abstract}
Resumo
0 objetivo do artigo é apresentar um quadro de referência de conceitos da Gestão da Sustentabilidade na Cadeia de Suprimentos (GSCS) para auxiliar pesquisas futuras na tentativa de integração intra e interorganizacional fundamentada em aspectos da sustentabilidade. Trata-se de um artigo teórico, cujo procedimento metodológico adotado foi o desk research em periódicos da área de gestão e operações, realizado em duas etapas. Na primeira, buscou-se visualizar os estudos da temática em seis importantes periódicos internacionais da área, totalizando 53 artigos entre 1954 e 2009. Esta etapa gerou uma evolução da temática, contribuindo para apontar tendências. Na segunda, foram revisados seis periódicos nacionais da área de administração. Selecionaram-se 11 artigos, publicados entre 1961 e 2009, resultando em um panorama da temática no contexto acadêmico brasileiro. 0 conceito de GSCS apareceu apenas em 2007, o que mostra a atualidade do tema, embora este seja a junção de temáticas anteriormente estudadas.
\end{abstract}

Palavras-chave

Sustentabilidade. Cadeia de suprimentos. Cadeia de suprimentos sustentável. Logística reversa. Desk research.

\section{Introdução}

A Gestão da Sustentabilidade* tem apresentado crescente interesse entre acadêmicos e gerentes que atuam na cadeia de suprimentos (VAN HOEK, 1999; SRIVASTAVA, 2007; SEURING; MULLER, 2008; VURRO; RUSSO; PERRINI, 2009; CHAKRABORTY, 2010; MANN et al., 2010), apresentando-se como uma questão crítica para o futuro da área de operações. Para o propósito deste artigo, Gestão da Sustentabilidade da Cadeia de Suprimentos (GSCS) é definida como um pensamento estratégico, transparente e integrado para atingir objetivos econômicos, sociais e ambientais numa coordenação sistêmica de processos interorganizacionais ao longo da cadeia (SEURING; MULLER, 2008; SRIVASTAVA, 2007).

*A sustentabilidade se baseia em um conjunto de novos valores, tratando-se de um conceito sistêmico que aborda perspectivas econômicas, sociais, ambientais, culturais, espaciais e éticas (SACHS, 2007).
Mas o que se quer dizer com o termo sustentabilidade em cadeias de suprimentos? No meio empresarial, esta aproximação tem ocorrido não somente por ser um procedimento amigável ambientalmente, mas porque tem gerado bons negócios e alta lucratividade (SRIVASTAVA, 2007). Apresenta-se não somente como um centro de custos operacionais (KLEINDORFER; SINGHAL; VAN WASSENHOVE, 2005), mas tem contribuído para economizar recursos, eliminar desperdícios e aumentar a produtividade, conforme sugere a hipótese de Porter ${ }^{\dagger}$. 0 termo sustentabilidade nesta abordagem pressupõe gestão socioambiental (VURRO;

tA hipótese de Porter foi desenvolvida em artigo seminal da Harvard Business Review (PORTER; VAN DER LINDE, 1995), sugerindo que a imposição de padrões ambientais estimula a busca de inovações tecnológicas para melhor utilização (e reutilização) dos insumos (matérias-primas, energia e trabalho) (KITZMANN e ASMUS, 2006). 
RUSSO; PERRINI, 2009, MANN et al. 2010), cadeias de suprimentos em circuito fechado (closed loop supply chains) (KLEINDORFER; SINGHAL; VAN WASSENHOVE, 2005) e ainda a inserção de preocupação social nas decisões empresariais (VURRO; RUSSO; PERRINI, 2009).

Neste contexto, importantes pilares aparecem como estratégia para alcançar a sustentabilidade em seu significado abrangente: o paradigma berço ao berço

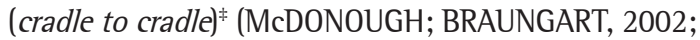
MANN et al., 2010) e o balanço entre as motivações financeiras e não financeiras (MANN et al., 2010). Embora a responsabilidade social venha sendo discutida exaustivamente em administração, pouca interação tem acontecido entre tais estudos e o campo de estudo das cadeias produtivas (CARTER; JENNINGS, 2004).

Referências aos termos "sustentabilidade" e "desenvolvimento sustentável” na literatura relacionada à economia, gestão e administração é crescente. Em 1990 a frequência destes termos era de 3/1000; em 2005, este indicador passou para 15/1000 (LINTON; KLASSEN; JAYARAMAN, 2007). Pilkington e Fitzgerald (2006), em uma análise da emergência dos temas mais pesquisados em gestão de operações entre 1994 e 2003, mostraram que o tema de sustentabilidade que não estava entre os dez tópicos mais estudados no período anterior (1994 a 1998), apareceu em nono lugar no período de 1999 a 2003. A emergência da temática pode ser atribuída à expansão das cadeias globais e ao esforço de governança conjunta empreendida por empresas e ONGs na execução de diversas formas de GSCS (VERMEULEN; SEURING, 2009).

Neste sentido, o escopo da GSCS parece estar-se ampliando, a partir de movimentos reativos aos programas de gestão ambiental para práticas mais proativas (SRIVASTAVA, 2007). Embora seja crescente o interessante da pesquisa em relação às questões socioambientais na gestão da cadeia de suprimentos (GCS), o foco em logística reversa prevalece, sendo a dimensão mais visível tanto para acadêmicos como práticos no assunto. Outras temáticas aparecem de forma limitada, pontual e estreita (MANN et al., 2010).

A atenção dada ao circuito fechado, ao "esverdeamento"§ e à sustentabilidade em cadeias de suprimento ainda é relativamente esparsa e dispersa, (CHAKRABORTY, 2010; MANN et al. 2010; SRIVASTAVA, 2007). Refere-se, na maioria das vezes, a fatores do design do produto, viabilidade de manufaturar subprodutos (componentes e destinação

\#Conforme o conceito de cradle to cradle os produtos e seus componentes devem ser criados para, ao final de seu uso, ser reutilizados com suas propriedades não desgastadas, isto é, como nutrientes tecnológicos, no chamado metabolismo tecnológico. Ou então voltar à natureza como nutrientes biológicos e não como poluentes, através do metabolismo biológico (McDONOUGH; BRAUNGART, 2002).

$\S$ Entendendo que verde (ou esverdeamento) se refere a tudo que é ecologicamente pensado (SVENSSON, 2007). correta dos resíduos); extensão da vida útil do produto (período correto de descarte de um produto); entre outros (KLEINDORFER; SINGHAL; VAN WASSENHOVE, 2005), buscando minimizar o impacto ambiental após sua vida útil. Assim a literatura consultada não cobre adequadamente todos os aspectos e facetas da GSCS, uma vez que a complexidade e ambiguidade da noção de sustentabilidade (SACHS, 2007) são reforçadas pela centralidade das questões sociais, como práticas de trabalho e obrigações sociais, contingentes à governança interorganizacional ao longo da cadeia (MATOS; HALL, 2007; MANN et al., 2010).

Então, o objetivo do artigo é apresentar um quadro de referência amplo para desenvolver conceitos e modelos, auxiliando pesquisas futuras na tentativa de integração intra e interorganizacional fundamentada em aspectos da sustentabilidade em relação à cadeia de suprimentos. Para isto, parte-se de uma perspectiva comparada de publicações internacionais e nacionais dentro dos aspectos e facetas da GSCS. A partir da revisão da literatura internacional, posiciona-se a produção nacional frente a esta temática. Para construção deste artigo, definiram-se alguns termos relevantes que apareceram ao longo da evolução deste campo de estudo, considerando-se, especialmente, o arcabouço teórico desenvolvido por Srivastava (2007). Espera-se contribuir com a apresentação de áreas-chave para estudos futuros, apontando tendências para pesquisadores brasileiros.

A importância e relevância deste estudo se justificam por subsidiar ações de empresas, do poder público e da sociedade civil, respectivamente, (1) na tomada de decisão para o desenvolvimento de produtos e gestão de fluxos reversos; (2) na elaboração de políticas públicas; (3) no direcionamento de programas de conscientização da sociedade no que tange a seus hábitos de consumo e descarte de produtos e embalagens, atenção às fontes de matérias-primas e cuidados com devastações de florestas e queimadas, entre outras questões críticas que precisam ser equacionadas.

Além desta introdução, discutem-se inicialmente os aspectos e facetas do campo de estudo em GSCS; a seguir são apresentados os procedimentos metodológicos utilizados para execução da pesquisa; e na terceira seção, a evolução da área na construção do conceito de sustentabilidade na Cadeia de Suprimentos. Os estudos encontrados na literatura internacional são apresentados na seção quatro, seguidos de um panorama dos estudos acadêmicos no contexto brasileiro. Nas conclusões, foram apontadas as áreas-chave e oportunidades para futuras pesquisas. 


\section{Uma visão dos aspectos e facetas da GSCS}

Gestão da Sustentabilidade na Cadeia de Suprimentos (GSCS) tem suas raizes na literatura de gestão ambiental e gestão da cadeia de suprimentos e diz respeito à influência e aos relacionamentos entre essas duas áreas de estudo. Este campo tem se desenvolvido a partir da prática de negócios e pesquisa e está passando por uma grande transformação. De fato, a temática, cujo foco principal era o custo e a entrega, está mudando sua natureza tática para um campo de natureza estratégica. Contudo, as questões e os desafios futuros enfrentados pelos gerentes e executivos somente agora estão sendo compreendidos (MELNYK et al., 2009). Na literatura consultada, a definição e o escopo da sustentabilidade em cadeia de suprimentos encontram uma grande amplitude, desde a compra verde, até a integração da sustentabilidade ao longo da cadeia de suprimentos (CARTER; ELLRAM, 1998; SRIVASTAVA, 2007), seguindo o caminho do fornecedor, produtor, consumidor, logística reversa (ZHU, SARKIS, 2004) e ainda a cadeia de suprimentos em circuito fechado (GUIDE; VAN WASSENHOVE, 2006a, b).

Existe literatura suficiente sobre os vários aspectos e facetas da GSCS, que compreende design verde (CHEN, 2001; ZHANG et al., 1997), plano de produção e controle para remanufatura (GUIDE; VAN WASSENHOVE, 2001), temas em manufatura verde e recuperação de produtos (GUIDE et al., 2006), logística reversa (CARTER, ELLRAM 1998; FLEISCHMANN et al., 2001) e desenho da rede logística (JAYARAMAN; PATTERSON; ROLLAND, 2003). Adicionalmente, Bloemhof-Ruwaard et al. (1995) estudam as interações entre pesquisa operacional e gestão ambiental, ressaltando a compra verde (ZHU; GENG 2001), ecologia industrial e os ecossistemas industriais (MIN; GALLE, 2001; VAN HOEK, 1999; ZHANG et al, 1997; ZHU, SARKIS, 2004).

Apesar do alcance da larga produção de logística reversa e da sua representatividade como uma área-chave para GSCS (MANN et al., 2010), por si só não é suficiente para integração estratégica da cadeia em direção à sustentabilidade (VAN HOEK, 1999). Afinal, GSCS diz respeito à "responsabilidade pela conduta do fornecedor que implica na diligência constante para manter reputação e legitimidade da empresa focal" (VERMEULEN; SEURING, 2009). Corbett (2009) e Vurro, Russo e Perrini (2009), por exemplo, ressaltam a necessidade de pensar além dos processos e fluxos logísticos, no trabalho com fornecedores de produtos e embalagens. Os autores recomendam desenvolver padrões para certificação e selos "verdes", mapear a pegada de carbono" (carbon footprints), desenvolver novas cadeias de bioenergia, capacitar toda cadeia para cumprir obrigações sociais.

A Figura 1 mostra que GSCS requer uma expansão da abordagem da cadeia direta, enfatizando aspectos econômicos, ambientais e sociais nas práticas e teorias de negócios. Essa perspectiva expandida gera questões tanto estratégicas quanto operacionais, entre as quais se destacam três tipos de atividades básicas (SRIVASTAVA, 2007): Design verde; Operação verde; Desenvolvimento de Mercado para Produtos Remanufaturados. A Figura 1 busca organizar os principais conceitos que delimitam o campo de estudo em GSCS, funcionando como o arcabouço teórico para este artigo.

Conforme mostra a Figura 1, as cadeias de suprimentos a jusante e a montante formam um circuito fechado quando são administradas de um modo coordenado em direção aos objetivos comuns numa perspectiva do triple bottom line, integrando lucros, sociedade e planeta na cultura, estratégia e operações interorganizacionais (SRIVASTAVA, 2007). Todavia "a assimilação do conceito não se dá igualmente entre as empresas pertencentes a uma determinada cadeia produtiva" (ALIGLERI; ALIGLERI; KRUGLIANSKAS, 2009). Esta condição sugere que o alcance da sustentabilidade só ocorre se for adaptada a cada empresa, levando em consideração os pontos fortes e fracos de cada uma (MANN et al., 2010). Dessa forma a consistência de uma cadeia em questões socioambientais é igual à capacidade de seu elo mais fraco, pois, se uma das funções falha ou é interrompida, provoca desequilíbrio nos outros elos, comprometendo a cadeia como um todo (ALIGLERI; ALIGLERI; KRUGLIANSKAS, 2009).

\subsection{Motivadores para inclusão da sustentabilidade na gestão da cadeia de suprimentos}

Vários são os motivadores para essa expansão e preocupação. Há empresas que são reativas a pressões externas, e há empresas que são proativas, buscando adicionar valor ao seu produto e ao seu negócio através dessas práticas. A perspectiva muda quando a sustentabilidade deixa de ser vista como fonte de custos para uma potencial fonte de vantagem competitiva (GUIDE; JAYARAMAN; LINTON, 2003; VAN HOEK, 1999).

I Criada há alguns anos, a “pegada de carbono" é uma tendência forte no continente europeu que começa a empurrar fornecedores de diversos segmentos industriais a prestar contas do impacto de suas atividades nas mudanças climáticas. 


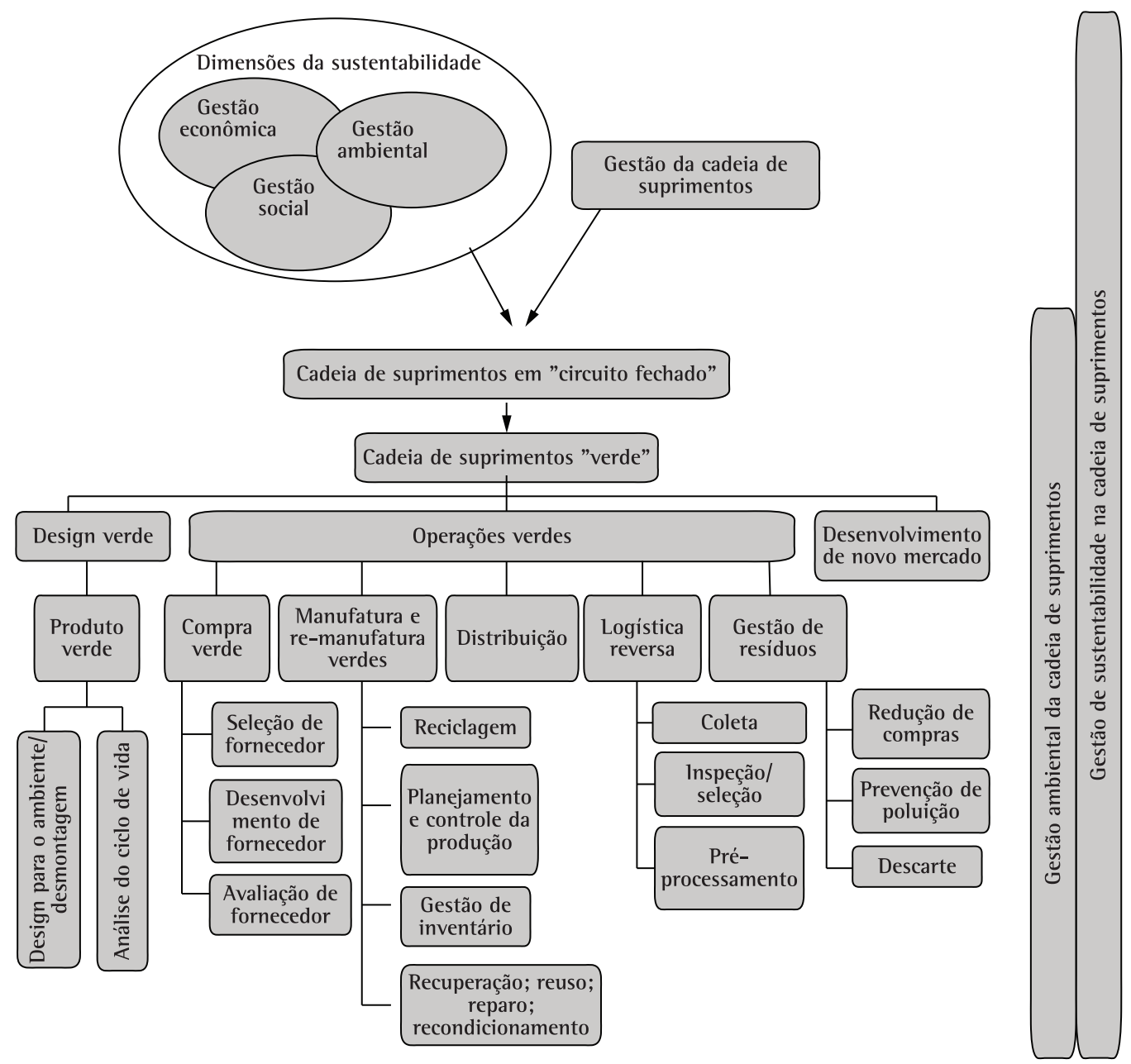

Figura 1. Classificação das temáticas envolvidas no estudo de GSCS. Fonte: elaborada pelos autores a partir de Srivastava (2007), Vurro, Russo e Perrini (2009) e Mann et al. (2010).

Quadro 1. Identificação dos stakeholders que afetam a estrutura da cadeia de suprimentos.

\begin{tabular}{|l|l|}
\hline Stakeholders & \multicolumn{1}{c|}{ Autores } \\
\hline \multirow{2}{*}{ Governo } & $\begin{array}{l}\text { Caincross, (1992), Corbett e Kleindorfer, (2001); Kleindorfer et al., (2005); Kopicki et al., (1993); Mann et al. } \\
\text { (2010), Matos e Hall, (2007), Melnyk et al. (2009), Murphy et al., (1996), Srivastava, (2007), Stock, (1992), } \\
\text { Vermeulen e Seuring, (2009) e Vurro et al. (2009) }\end{array}$ \\
\hline Fornecedores & Carter e Ellran, (1998), Stock, (1992), Zhu e Sarkis, (2004), Corbet, (2009) e Vermeulen e Seuring, (2009) \\
\hline Compradores & $\begin{array}{l}\text { Corbett e Kleindorfer, (2001), Kopicki et al., (1993), Stock, (1992), Zhu e Geng, (2001), Zhu e Sarkis, (2004) e } \\
\text { Vermeulen e Seuring, (2009) }\end{array}$ \\
\hline Competidores & $\begin{array}{l}\text { Guide et al., (2003), Kleindorfer et al., (2005), Porter, Van Der Linde, (1995), Stock, (1992), Van Hoek, (1999) e } \\
\text { Vermeulen e Seuring, (2009) }\end{array}$ \\
\hline Comunidade & Kleindorfer et al., (2005), Snir, (2001) e Vurro et al. (2009) \\
\hline ONGs & Carter e Ellran, (1998), Kleindorfer et al., (2005), Vurro et al. (2009) e Vermeulen e Seuring, (2009) \\
\hline
\end{tabular}

Fonte: Elaboração própria.

A revisão da literatura aponta que as forças reguladoras têm recebido maior atenção como motivadores da sustentabilidade, pois geralmente credita-se a elas maior influência na estruturação de canais reversos das empresas, sendo diretamente afetadas por um ou multistakeholders: clientes, fornecedores, competidores e agentes governamentais (Quadro 1).
A força do ambiente institucional regulador consiste em órgãos governamentais e agentes agregados como consumidores, grupos lobistas e ONGs que influenciam as entidades governamentais e reguladoras. É visível que as empresas estão mais dispostas a melhorar seu desempenho quando pressões públicas resultam em fortes regulamentações (SNIR, 2001; MELNYK et al., 2009). 
Algumas vezes, a própria empresa pressiona a criação de regulamentações se ela desenvolveu uma tecnologia ambientalmente amiga, e acredita que The dariam vantagem competitiva (KLEINDORFER; SINGHAL; VAN WASSENHOVE, 2005). Se antes eram principalmente estimulados por governos, agora um vasto número de diferentes códigos de conduta, padrões administrativos, esquemas de certificação, selos verdes e sistemas de governança globais estão sendo gerados pelos compromissos unilaterais privados. Bartley (2007) lembra que a globalização das cadeias de produção e a falta de capacidade regulatória dos Estados, fora das suas fronteiras, têm levado a novas formas de "governança global".

A maioria dessas formas de regulação privada atinge as grandes corporações transnacionais, mas, em muitos casos, elas influenciam empresas menores que fazem parte da sua cadeia de produção (CONROY, 2007). Por exemplo, o fato de a rede de supermercados Wal Mart incorporar a liderança em sustentabilidade como uma estratégia, "poderá gerar milhões em economia e influenciar 60.000 fornecedores, provocando a incorporação de práticas em direção à sustentabilidade numa escala jamais vista no mundo dos negócios" (ROSENBURG, 2006).

Neste contexto, as pressões institucionais dos consumidores e de requerimentos regulatórios, podem representar lucratividade para as empresas e consequentes impactos nas práticas da cadeia de suprimentos, por diversos motivadores (SRIVASTAVA, 2007). Entre eles, a escassez de recursos naturais já enfrentada atualmente e sua intensificação futura fortalecerão a necessidade de pesquisar os valores dos resíduos. Outro motivador é o preço dos recursos não renováveis, que aumentará conforme crescer sua escassez, o que colocará tais recursos progressivamente na agenda de negócios (SVENSSON, 2007). Neste contexto, espera-se um aumento rápido de investimentos em tecnologias, operações e cadeias de suprimentos pelas forças do ambiente institucional enumeradas por Kleindorfer, Singhal e Van Wassenhove (2005): Custo de materiais e energia, pressão pública sobre desempenho ambiental, de saúde e segurança; crescente conscientização de questões do triple botton line; crescente movimento antiglobalização.
Essas forças apontam para a cadeia de suprimentos cuja inclusão representa uma perspectiva sistêmica para atingir as iniciativas em direção à sustentabilidade. Então, a perspectiva muda de "esverdeamento" como um fardo, para uma potencial fonte de vantagem competitiva (VAN HOEK, 1999). Dentro deste conceito, há uma mudança de foco da minimização de custos para criação de valor ao longo da cadeia produtiva (KLEINDORFER; SINGHAL; VAN WASSENHOVE, 2005). Na próxima seção, apresentam-se os procedimentos metodológicos.

\section{Procedimentos metodológicos}

Trata-se de um artigo teórico cujo procedimento metodológico adotado é o desk research, baseado em um conjunto de periódicos nacionais e internacionais em Gestão de Operações e Cadeia de Suprimentos. Com base no arcabouço conceitual desenvolvido por Srivastava (2007), apresentado na Figura 1, buscou-se, em periódicos nacionais e internacionais disponíveis nos portais eletrônicos EBSCO, PROQUEST, CAPES e SCIELO, as seguintes palavras-chave: compra verde/sustentável (CV) (green/environmental purchasing); produto verde (PV) (green product); logística verde (LV) (green/environmental logistics); logística reversa (LR) (reverse logistics); cadeia reversa (CR) (reverse chain); cadeia de suprimentos em circuito fechado (CSCF) (closed-loop supply chain); cadeia de suprimentos verde (CSV) (green supply chain); e cadeia de suprimentos sustentável (SCS) (sustainable supply chain). Essas palavras foram verificadas entre o título, o resumo e as palavras-chave dos artigos, conforme ferramentas de busca disponiveis nos portais consultados. 0 trabalho se dividiu em duas etapas:

Análise de seis importantes periódicos internacionais da área de gestão operações, logística e cadeia de suprimentos em língua inglesa, da data disponível nos portais de busca até 2009 (Quadro 2). São eles: Journal of Business Logistics;Production and Operations Management Journal; Journal of Operations Management; International Journal of Logistics Management; International Journal of Operations and Production Management; e Management Science. Desta busca, resultou o levantamento dos principais

Quadro 2. Periódicos internacionais pesquisados.

\begin{tabular}{|c|c|c|c|c|}
\hline & Periódico & Qualis' & Fonte de pesquisa & Disponibilidade \\
\hline \multirow{6}{*}{ } & Journal of Business Logistics (JBL) & $n / d$ & Ebsco e ProQuest & de 1987 a 2009 \\
\hline & Production and Operations Management Journal (POM) & $\mathrm{n} / \mathrm{d}$ & Ebsco e ProQuest & de 1999 a 2009 \\
\hline & Journal of Operations Management (JOM) & $\mathrm{n} / \mathrm{d}$ & Ebsco e ProQuest & de 1980 a 2009 \\
\hline & International Journal of Logistics Management (IJLM) & $\mathrm{n} / \mathrm{d}$ & Ebsco e ProQuest & de 1998 a 2009 \\
\hline & International Journal of Operations and Production Management (1JOPM) & $\mathrm{A} 1$ & Ebsco e ProQuest & de 1980 a 2009 \\
\hline & Management Science (MS) & $\mathrm{n} / \mathrm{d}$ & Ebsco e ProQuest & de 1954 a 2009 \\
\hline
\end{tabular}

Classificação Qualis Capes 2007. Fonte: Elaboração própria. 
conceitos envolvidos na temática de GSCS, resultando na periodização dos estudos internacionais sobre a gestão da sustentabilidade na cadeia de suprimentos.

Análise de artigos nacionais publicados em revistas nacionais em português selecionadas segundo critério Qualis A1, A2, B1 e B2 da CAPES na área de Administração em 2007: Gestão e Produção (UFSCar); Produção (ABEPRO); Revista de Administração de Empresas -RAE e RAE-eletrônica- (EAESP-FGV); Revista de Administração da Universidade de São Paulo - RAUSP - (FEA-USP); e Revista de Administração Contemporânea - RAC- (ANPAD), pois se caracterizam como importantes fontes de pesquisas nessa área no Brasil . 0 Quadro 3 abaixo exibe a lista de periódicos com as respectivas datas de publicações disponíveis em portais eletrônicos, conforme os critérios definidos para o presente artigo.

0 objetivo foi investigar: a) o histórico e as tendências da temática pesquisada nas publicações internacionais relevantes; b) o histórico e as tendências da temática nas publicações nacionais relevantes; c) as disparidades e similaridades entre as pesquisas nacionais e internacionais. Além disso, foi realizada uma análise mais detalhada das publicações nacionais com vistas a oferecer um panorama da pesquisa em gestão da sustentabilidade na cadeia de suprimentos no Brasil, assim como sugerir lacunas para pesquisas futuras. 0 processo de identificação e seleção de artigos resultou em uma lista de referência de 67 artigos, entre os quais 11 nacionais publicados entre 2006 e 2009 e 56 internacionais entre 1995 e 2009.

\section{0 que os periódicos internacionais dizem}

A mais antiga referência localizada na literatura sobre estratégia de reversão de materiais, data do início dos anos 70. Zikmund e Stanton (1971) utilizaram o termo Reverse Distribution, referenciando-se à similaridade dos conceitos de distribuição, aplicados no sentido inverso, devido à necessidade de recolhimento de materiais sólidos provenientes do pós-consumo para reutilização pelo produtor. Mais tarde, Ginter e Starling (1978) utilizaram o termo Reverse Distribution Channels numa publicação do California Management Review, enfocando a questão da reciclagem e suas vantagens econômicas e ecológicas, enfatizando a importância dos canais de distribuição reversos como contribuinte fundamental na viabilidade econômica do processo de recuperação dos materiais.

Em 1981, Lambert e Stock (1981) descreviam a distribuição reversa como o produto "indo na contramão de uma rua de sentido único, porque a grande maioria dos embarques de produtos flui em uma direção". Já em 1982, Barnes (1982) utilizou o termo Logística Reversa numa publicação do Journal of Macromarketing, em que trata da importância crescente da reciclagem em benefício dos negócios e da sociedade.

A literatura revisada revela, conforme mostra o Quadro 4, que o conceito de logística reversa ganhou força desde a década de 1980, mas apenas a partir dos anos 1990 passou a ser discutida com mais intensidade. Os estudos de logística reversa concentram-se no espaço interno das organizações

Quadro 3. Revistas nacionais pesquisadas.

\begin{tabular}{|c|c|c|c|c|}
\hline & Periódico (instituição responsável) & Qualis $^{1}$ & Fonte de pesquisa & Disponibilidade \\
\hline \multirow{9}{*}{ 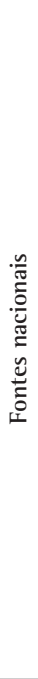 } & $\begin{array}{l}\text { Revistas Gestão e Produção } \\
\text { (Universidade Federal de São Carlos - UFSCar) }\end{array}$ & A2 & Portal Capes e Scielo Brasil & de 2000 a 2009 \\
\hline & $\begin{array}{l}\text { Revista Produção (Associação Brasileira de } \\
\text { Engenharia de Produção - ABEPRO) }\end{array}$ & $\mathrm{A} 2$ & Portal Capes e Scielo Brasil & de 2002 a 2009 \\
\hline & $\begin{array}{l}\text { Revista de Administração de Empresas Eletrônica } \\
\text { RAE eletrônica ( Fundação Getúlio Vargas) }\end{array}$ & B1 & Portal Capes e Scielo Brasil & de 2002 a 2008 \\
\hline & $\begin{array}{l}\text { Revista de Administração de Empresas - RAE } \\
\text { Fundação Getúlio Vargas) }\end{array}$ & B1 & Portal Capes e Scielo Brasil & de 1961 a 2009 \\
\hline & $\begin{array}{l}\text { Revista de Administração } \\
\text { Contemporânea - RAC - (Associação Nacional } \\
\text { dos Programas de Pós-graduação em } \\
\text { Administração - ANPAD) }\end{array}$ & B1 & Site da Anpad http://www.anpad.org.br/periodicos/ & de 1997 a 2009 \\
\hline & $\begin{array}{l}\text { Revista de Administração Contemporânea } \\
\text { Eletrônica - RAC eletrônica (ANPAD) }\end{array}$ & B1 & Site da Anpad http://www.anpad.org.br/periodicos/ & de 2007 a 2009 \\
\hline & $\begin{array}{l}\text { Revista Eletrônica de Administração - REAd } \\
\text { (Universidade Federal do Rio Grande do Sul) }\end{array}$ & B2 & Site as revista REAd http://www.read.ea.ufrgs.br/ & de 1995 a 2009 \\
\hline & $\begin{array}{l}\text { Revista de Administração Makenzie - RAM- } \\
\text { (Universidade Mackenzie) }\end{array}$ & B2 & $\begin{array}{l}\text { Site da revista RAM http://www3. } \\
\text { mackenzie.br/editora/index.php/ RAM/issue/ } \\
\text { archive?issuesPage=1\#issues }\end{array}$ & de 2000 a 2009 \\
\hline & $\begin{array}{l}\text { Revista de Administração da Universidade de São } \\
\text { Paulo - RAUSP - ( Universidade de São Paulo ) }\end{array}$ & B2 & Site da Universidade de São Paulo http://www.usp.br & de 1989 a 2009 \\
\hline
\end{tabular}

'Classificação Qualis da Capes em 2007. Fonte: Elaboração própria. 
Dias, S. L. F. G. et. al.

Sustentabilidade e cadeia de suprimentos...nacionais e internacionais. Produção, v. 22, n. 3, p. 517-533, maio/ago. 2012

\begin{tabular}{|c|c|c|c|c|c|c|c|c|c|c|}
\hline 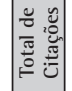 & $m$ & 0 & $\sim$ & $N$ & 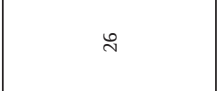 & 0 & $\underline{0}$ & - & - & \begin{tabular}{l}
0 \\
$ٌ$ \\
\hdashline
\end{tabular} \\
\hline 8 & & & & & 㤩产总总 & & & & & - \\
\hline$\stackrel{\infty}{\circ}$ & & & & & 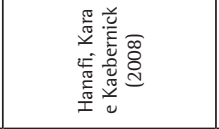 & 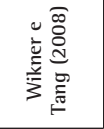 & 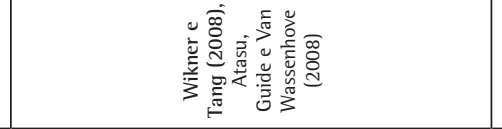 & 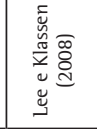 & & $\diamond$ \\
\hline of & & & & & 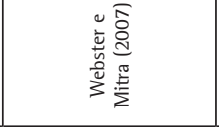 & 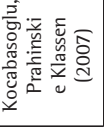 & 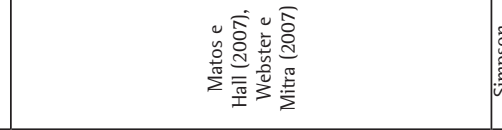 & 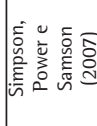 & 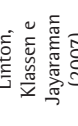 & 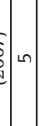 \\
\hline 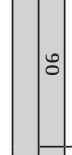 & & & & 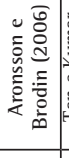 & 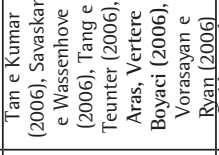 & 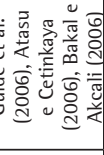 & 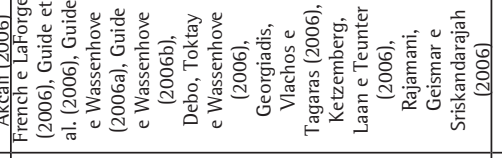 & 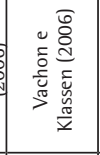 & & $\infty$ \\
\hline 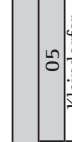 & 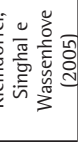 & & & & 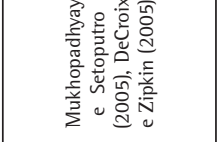 & & 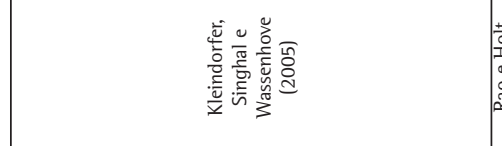 & 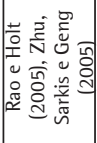 & & in \\
\hline t & & & 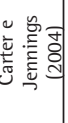 & & 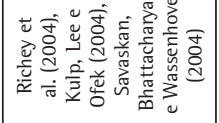 & & 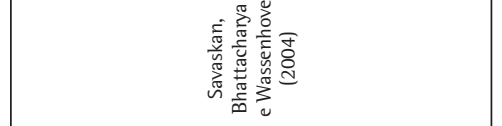 & 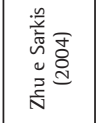 & & in \\
\hline 资 & & & & & 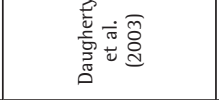 & & 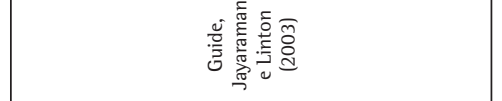 & & & $\sim$ \\
\hline o & & & & & 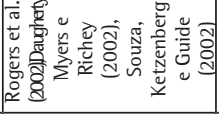 & & & 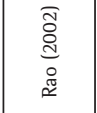 & & + \\
\hline $\bar{\sigma}$ & 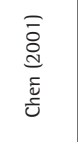 & & 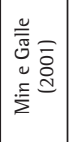 & & 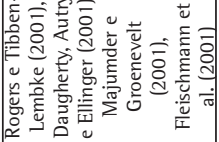 & 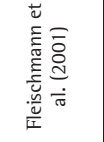 & 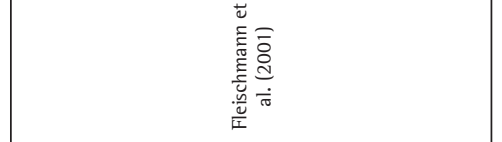 & & & 0 \\
\hline 8 & & & & & & & & & & 0 \\
\hline ร) & & & & & 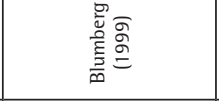 & & & & & - \\
\hline 吕 & & & & & 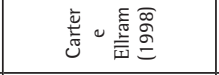 & & & & & - \\
\hline â & & & & & 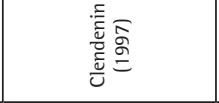 & & 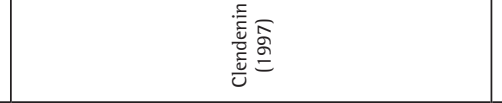 & & & - \\
\hline \& & & & & 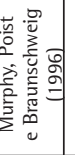 & 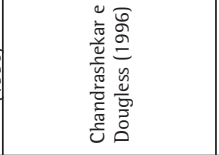 & & & & & \\
\hline ڤ & 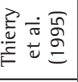 & & & & & & & & & - \\
\hline 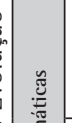 & 웜 & & ty & 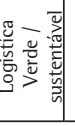 & 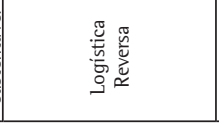 & 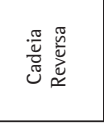 & 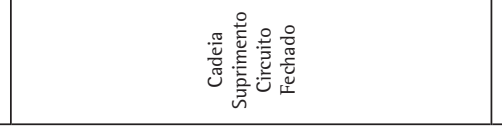 & 总 & \multirow{2}{*}{\multicolumn{2}{|c|}{ 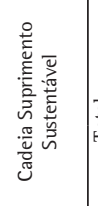 }} \\
\hline 惡 & 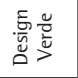 & \multicolumn{7}{|c|}{ 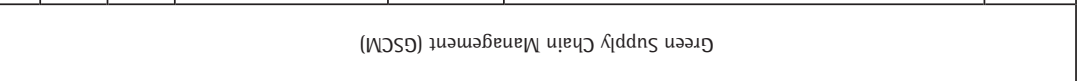 } & & \\
\hline
\end{tabular}


empresariais e na sua capacidade de implementar políticas de reutilização e reciclagem de resíduos e/ou fatores agregados a produtos e serviços de uma organização (VAN HOEK, 1999). Como a logística reversa tem ganhado crescente interesse, torna-se relevante questionar se é suficiente o limitado esforço de "esverdeamento" de um segmento da cadeia de suprimentos e ainda de uma única empresa (SRIVASTAVA, 2007).

Uma linha evolutiva foi preparada, levando em conta documentos publicados na área de GSCS nos periódicos internacionais de maior relevância na área de operações, logística e cadeia de suprimentos, disponíveis nos portais eletrônicos EBSCO e PROQUEST com as seguintes palavras-chave: green/environmental purchasing; Green product Green/environmental logistics; reverse logistics; reverse chain; closed-loop supply chain; green supply chain; sustainable supply chain. Diante disto, o Quadro 4 apresenta, ainda, a evolução da GSCS no tempo, de acordo com seis importantes periódicos da área, confirmando que o termo "logística reversa" é a palavra-chave mais citada dentro da temática pesquisada. Foi feita análise de seis importantes periódicos internacionais da área de gestão de operações, logística e cadeia de suprimentos em língua inglesa, disponíveis nos portais de busca até 2009. Desta busca resultou o levantamento dos principais conceitos envolvidos na temática de GSCS, resultando na periodização dos estudos internacionais sobre a gestão da sustentabilidade na cadeia de suprimentos.

0 Quadro 4 mostra, adicionalmente, que no período de 1995 a 1997, os temas produto verde (THIERRY et al., 1995), logística verde (MURPHY; POIST; BRAUNSCHWEIG , 1996) e logística reversa (CHANDRASHEKAR; DOUGLESS, 1996; CLENDENIN, 1997) começaram a aparecer nos periódicos da área de operações. Em 1997 ocorreu a primeira menção a "fechar o circuito da cadeia" (CLENDENIN, 1997), embora o conceito não tenha sido claramente definido até 2001 (FLEISCHMENN et al., 2001). No entanto, é somente a partir de 2003 que este conceito passa a ser estudado de maneira sistemática nos anos seguintes. Dentro do conceito Cadeia de Suprimento em Circuito Fechado - "Closed-Loop Supply Chain" (GUIDE; JAYARAMAN; LINTON, 2003), há uma mudança de foco da minimização de custos para criação de valor (KLEINDORFER; SINGHAL; VAN WASSENHOVE, 2005). A cadeia direta e a reversa formam um circuito fechado quando administradas de forma coordenada rumo a um objetivo comum de maximização de lucros.

Entre 2001 e 2002, estudos em logística reversa ganharam ainda mais força, mas percebe-se que as pesquisas começaram a se expandir pela temática da GSCS, com estudos em cadeia reversa (FLEISCHMANN et al., 2001) e em cadeia de suprimentos verde (RAO, 2002). Foi entre 2003 e 2005 que se observou um grande impulso dado à temática, período que concentra estudos nos temas produto verde (KLEINDORFER; SINGHAL; VAN WASSENHOVE, 2005), cadeia reversa e cadeia de suprimentos em circuito fechado com grande destaque, cadeia de suprimentos verde, principalmente, logística reversa.

Desde 2006, tem aumentado o número de estudos sobre produto verde, logistica verde, logística reversa, cadeia reversa, cadeia de suprimentos em circuito fechado e cadeia de suprimentos verde, indicando a expansão da abordagem para uma visão mais sistêmica e completa.

Importante ressaltar que, nos periódicos internacionais da área de operações, o conceito de gestão da sustentabilidade em cadeia de suprimentos apareceu apenas em 2007 (LINTON; KLASSEN; JAYARAMAN, 2007), o que mostra a atualidade do tema, embora este seja apenas a junção de todas as temáticas estudadas em separado, numa visão sistêmica de toda a cadeia produtiva e seus componentes.

\section{Contextualização do tema em publicações brasileiras}

No contexto dos artigos nacionais pesquisados, onze artigos foram encontrados entre 2003 e 2009 a partir das palavras-chave selecionadas. Mais da

Tabela 1. Publicações nacionais por ano e palavra-chave.

\begin{tabular}{llcc}
\hline \multicolumn{1}{c}{ Autores } & Ano & Palavras-chave & Total \\
\hline Giacobo, Estrada e Sérgio & 2003 & logística reversa & 1 \\
Gonçalves-Dias & 2006 & logística reversa, logística verde & \\
Chaves e Batalha & 2006 & logística reversa & 6 \\
Gonçalves e Marins & 2006 & logística reversa & \\
Gonçalves-Dias e Teodósio & 2006 & logística reversa, cadeia reversa & \\
Rezende, Dalmácio e Slomski & 2006 & logística reversa & 2 \\
Guarnieri et al. & 2006 & logística reversa & 1 \\
Adlmaier e Sellitto & 2007 & logística reversa & 1 \\
Pedroso e Zwicker & 2007 & cadeia reversa & 1 \\
Giovannini e Kruglianskas & 2008 & logística reversa & \\
Aquino, Castilho Junior e Pires & 2009 & logística reversa, cadeia reversa & \\
\hline
\end{tabular}

Fonte: dados da pesquisa. 
Dias, S. L. F. G. et. al.

Sustentabilidade e cadeia de suprimentos...nacionais e internacionais. Produção, v. 22, n. 3, p. 517-533, maio/ago. 2012 PROQ

Quadro 5. Evolução da temática da GSCS nas revistas nacionais.

\begin{tabular}{|c|c|c|c|c|c|c|c|}
\hline Revista & Autores & Ano & $\begin{array}{l}\text { Palavras- } \\
\text { chave }\end{array}$ & Objetivo & Metodologia & Resultados & $\begin{array}{l}\text { Instituição dos } \\
\text { autores }\end{array}$ \\
\hline \multirow{4}{*}{ 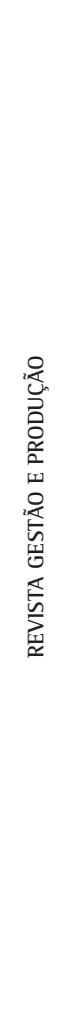 } & $\begin{array}{l}\text { Gonçalves- } \\
\text { Dias }\end{array}$ & 2006 & $\begin{array}{l}\text { logística } \\
\text { reversa, } \\
\text { logística } \\
\text { verde }\end{array}$ & $\begin{array}{c}\text { É analisado o caso da } \\
\text { reciclagem da embalagem PET, } \\
\text { para problematizar os fatores } \\
\text { impulsionadores e limitadores } \\
\text { da expansão dessa estratégia } \\
\text { de gestão ambiental no cenário } \\
\text { brasileiro. }\end{array}$ & $\begin{array}{c}\text { estudo } \\
\text { exploratório }\end{array}$ & $\begin{array}{l}\text { Apesar de existirem avanços } \\
\text { significativos para o volume } \\
\text { reciclado, ainda persistem } \\
\text { importantes desafios quanto } \\
\text { a normas de regulação da } \\
\text { cadeia reversa, estratégias } \\
\text { de inovação tecnológica } \\
\text { e gerencial e, sobretudo, } \\
\text { interações dos atores na } \\
\text { cadeia. }\end{array}$ & $\begin{array}{l}\text { Fundação Getúlio } \\
\text { Vargas - FGV e } \\
\text { Universidade de São } \\
\text { Paulo - USP }\end{array}$ \\
\hline & $\begin{array}{l}\text { Chaves e } \\
\text { Batalha }\end{array}$ & 2006 & $\begin{array}{l}\text { logística } \\
\text { reversa }\end{array}$ & $\begin{array}{l}\text { Estuda o papel e a relevância } \\
\text { dos Centros de Coleta de } \\
\text { embalagens recicláveis como } \\
\text { fator de atração de clientes } \\
\text { aos supermercados. }\end{array}$ & $\begin{array}{l}\text { estudo } \\
\text { de caso }\end{array}$ & $\begin{array}{c}\text { Constatou-se que a } \\
\text { existência de Centros de } \\
\text { Coleta não é um fator } \\
\text { de influência na escolha } \\
\text { do local de compra pelos } \\
\text { consumidores. }\end{array}$ & $\begin{array}{l}\text { Universidade Federal de } \\
\text { São Carlos - UFSCar }\end{array}$ \\
\hline & $\begin{array}{l}\text { Gonçalves e } \\
\text { Marins }\end{array}$ & 2006 & $\begin{array}{l}\text { logística } \\
\text { reversa }\end{array}$ & $\begin{array}{l}\text { Apresentar uma aplicação da } \\
\text { Logística Reversa e discutir } \\
\text { seus principais aspectos, como } \\
\text { definição de Logística Reversa, } \\
\text { ciclo de vida do produto, } \\
\text { motivos e destinos do } \\
\text { retorno, além dos fatores que } \\
\text { influenciam sua eficiência. }\end{array}$ & $\begin{array}{l}\text { estudo } \\
\text { de caso }\end{array}$ & $\begin{array}{l}\text { A implementação de um } \\
\text { processo de Logística } \\
\text { Reversa além de conduzir } \\
\text { à satisfação de exigências } \\
\text { normativas, pode levar } \\
\text { a uma redução de custo } \\
\text { no produto acabado, } \\
\text { principalmente quando } \\
\text { existe o reuso do material } \\
\text { de descarte, entre outros } \\
\text { benefícios. }\end{array}$ & $\begin{array}{l}\text { Universidade Estadual } \\
\text { Paulista - UNESP }\end{array}$ \\
\hline & $\begin{array}{l}\text { Aquino, } \\
\text { Castilho } \\
\text { Junior e } \\
\text { Pires }\end{array}$ & 2009 & $\begin{array}{l}\text { logística } \\
\text { reversa, } \\
\text { cadeia } \\
\text { reversa }\end{array}$ & $\begin{array}{l}\text { Propor uma forma de } \\
\text { organização logística para as } \\
\text { associações de catadores de } \\
\text { materiais recicláveis realizarem } \\
\text { a comercialização direta de } \\
\text { seus produtos às indústrias } \\
\text { recicladoras, visando à } \\
\text { agregação de valor. }\end{array}$ & survey & $\begin{array}{l}\text { A partir da organização das } \\
\text { associações de catadores em } \\
\text { rede, todas elas conseguiriam } \\
\text { comercializar produtos } \\
\text { diretamente com indústrias } \\
\text { recicladoras, e, juntas, } \\
\text { obteriam uma agregação de } \\
\text { 32\% no valor dos produtos } \\
\text { comercializados. }\end{array}$ & $\begin{array}{l}\text { Universidade Federal de } \\
\text { Santa Catarina - UFSC }\end{array}$ \\
\hline \multirow{3}{*}{ 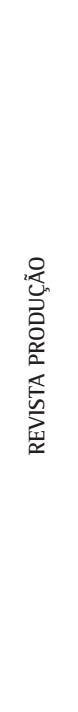 } & $\begin{array}{l}\text { Gonçalves- } \\
\text { Dias e } \\
\text { Teodósio }\end{array}$ & 2006 & $\begin{array}{l}\text { logística } \\
\text { reversa, } \\
\text { cadeia } \\
\text { reversa }\end{array}$ & $\begin{array}{l}\text { Discutir as possiblidades, } \\
\text { limites e desafios da } \\
\text { reciclagem de PET. }\end{array}$ & $\begin{array}{c}\text { estudo } \\
\text { exploratório }\end{array}$ & $\begin{array}{l}\text { Apesar do avanço no volume } \\
\text { de reciclagem, nenhum } \\
\text { dos setores, seja público } \\
\text { ou privado, consegue } \\
\text { individualmente organizar-se } \\
\text { para o alcance da efetividade } \\
\text { operacional e ambiental } \\
\text { desejável no cenário } \\
\text { brasileiro. }\end{array}$ & $\begin{array}{c}\text { Escola de } \\
\text { Administração } \\
\text { de Empresas da } \\
\text { Fundação Getúlio } \\
\text { Vargas - EAESP - FGV }\end{array}$ \\
\hline & $\begin{array}{l}\text { Guarnieri } \\
\text { et al. }\end{array}$ & 2006 & $\begin{array}{l}\text { logística } \\
\text { reversa }\end{array}$ & $\begin{array}{c}\text { Propor uma adptação do } \\
\text { Warehouse Management } \\
\text { Systens (WMS) tradicional, de } \\
\text { forma a ser possível utilizá-lo } \\
\text { também para o gerenciamento } \\
\text { da cadeia de suprimentos } \\
\text { reversa. }\end{array}$ & $\begin{array}{c}\text { estudo } \\
\text { exploratório }\end{array}$ & $\begin{array}{l}\text { A maioria das funções do } \\
\text { WMS tradicionalmente } \\
\text { utilizadas para gerenciar a } \\
\text { logística direta também pode } \\
\text { ser utilizada na logística } \\
\text { reversa. }\end{array}$ & $\begin{array}{l}\text { CEFET - PR } \\
\text { UNIPAN - PR }\end{array}$ \\
\hline & $\begin{array}{l}\text { Adlmaier e } \\
\text { Sellitto }\end{array}$ & 2007 & $\begin{array}{l}\text { logística } \\
\text { reversa }\end{array}$ & $\begin{array}{l}\text { Comparar o processo original de } \\
\text { exportação, como embalagens } \\
\text { descartáveis, com o novo } \\
\text { processo, com as embalagens } \\
\text { retornáveis, que opera um canal } \\
\text { de distribuição reverso de peças } \\
\text { para motores a diesel. }\end{array}$ & $\begin{array}{l}\text { estudo } \\
\text { de caso }\end{array}$ & $\begin{array}{l}\text { A introdução de uma prática } \\
\text { específica da logística } \\
\text { reversa, o uso de embalagens } \\
\text { retornáveis, trouxe três tipos } \\
\text { de resultados a uma empresa } \\
\text { exportadora: benefícios } \\
\text { financeiros, redução de } \\
\text { ataques ambientais e } \\
\text { benefícios logísticos. }\end{array}$ & $\begin{array}{l}\text { Universidade do } \\
\text { Valor do Rio dos } \\
\text { Sinos - UNISINOS }\end{array}$ \\
\hline 迆 & $\begin{array}{l}\text { Giovannini e } \\
\text { Kruglianskas }\end{array}$ & 2008 & $\begin{array}{l}\text { logística } \\
\text { reversa }\end{array}$ & $\begin{array}{l}\text { Mostrar os fatores críticos } \\
\text { de sucesso para a criação } \\
\text { de um processo sustentável } \\
\text { de reciclagem que envolve a } \\
\text { coordenação de muitos agentes } \\
\text { econômicos e sociais. }\end{array}$ & $\begin{array}{l}\text { estudo } \\
\text { de caso }\end{array}$ & $\begin{array}{l}\text { Os fatores críticos de sucesso } \\
\text { são visão estratégica e } \\
\text { comprometimento de alta } \\
\text { administração, estrutura de } \\
\text { logística reversa adequada } \\
\text { e estrutura de negócio } \\
\text { que garante resultados } \\
\text { econômicos e sua adequada } \\
\text { distribuição. }\end{array}$ & FEA - USP \\
\hline
\end{tabular}


Quadro 5. Continuação...

\begin{tabular}{|c|c|c|c|c|c|c|c|}
\hline Revista & Autores & Ano & $\begin{array}{l}\text { Palavras- } \\
\text { chave }\end{array}$ & Objetivo & Metodologia & Resultados & $\begin{array}{l}\text { Instituição dos } \\
\text { autores }\end{array}$ \\
\hline 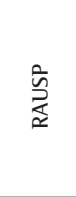 & $\begin{array}{l}\text { Pedroso e } \\
\text { Zwicker }\end{array}$ & 2007 & $\begin{array}{l}\text { cadeia } \\
\text { reversa }\end{array}$ & $\begin{array}{l}\text { Discutir a sustentabilidade } \\
\text { corporativa no escopo da } \\
\text { cadeia reversa de suprimentos. }\end{array}$ & $\begin{array}{l}\text { estudo de } \\
\text { caso }\end{array}$ & $\begin{array}{l}\text { Os fatores críticos de } \\
\text { sucesso identificados foram } \\
\text { a inovação tecnológica, a } \\
\text { viabilidade econômica, as } \\
\text { ações integradas na cadeia } \\
\text { para a sustentabilidade } \\
\text { corporativa. }\end{array}$ & $\begin{array}{l}\text { Universidade de São } \\
\text { Paulo - USP }\end{array}$ \\
\hline \multirow[b]{2}{*}{ 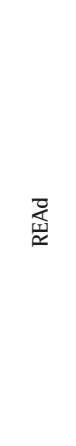 } & $\begin{array}{l}\text { Giacobo, } \\
\text { Estrada e } \\
\text { Ceretta }\end{array}$ & 2003 & $\begin{array}{l}\text { logística } \\
\text { reversa }\end{array}$ & $\begin{array}{c}\text { Mostrar a satisfação do cliente } \\
\text { no pós-venda através da } \\
\text { logística reversa. }\end{array}$ & $\begin{array}{l}\text { estudo } \\
\text { teórico- } \\
\text { conceitual }\end{array}$ & $\begin{array}{l}\text { A estratégia de logística } \\
\text { reversa é mais que um centro } \\
\text { de custo, ela satisfaz as } \\
\text { expectativas dos clientes e } \\
\text { pode oferecer um diferencial } \\
\text { competitivo diante da } \\
\text { concorrência. }\end{array}$ & $\begin{array}{c}\text { Universidade Federal de } \\
\text { Santa Maria - UFSM }\end{array}$ \\
\hline & $\begin{array}{l}\text { Rezende, } \\
\text { Dalmácio e } \\
\text { Slomski }\end{array}$ & 2006 & $\begin{array}{l}\text { logística } \\
\text { reversa }\end{array}$ & $\begin{array}{l}\text { Avaliar o impacto econômico e } \\
\text { financeiro da logística reversa } \\
\text { no segmento de distribuição } \\
\text { de matérias-primas } \\
\text { farmacêuticas. }\end{array}$ & $\begin{array}{l}\text { pesquisa- } \\
\text { ação }\end{array}$ & $\begin{array}{l}\text { A implementação da logística } \\
\text { reversa pode ser considerada } \\
\text { um diferencial estratégico, } \\
\text { contribuindo para o } \\
\text { aprimoramento das atividades } \\
\text { e trazendo benefícios para } \\
\text { clientes, fornecedores e } \\
\text { acionistas, e gera vantagem } \\
\text { competitiva. }\end{array}$ & FEA/USP, FUCAPE \\
\hline
\end{tabular}

Fonte: Dados da pesquisa

metade desses artigos foram publicados em 2006, sendo que dez deles fizeram referência ao conceito de logística reversa (Tabela 1), enquanto apenas um tratou também de logística verde (GONÇALVES-DIAS, 2006) e outro de cadeia reversa (GONÇALVES-DIAS; TEODOS10, 2006). 0 artigo de Pedroso e Zwicker (2007) foi selecionado abordando o conceito de cadeia reversa, mas em seu desenvolvimento teórico aborda, como era esperado, o conceito de logística reversa.

Diante de um número pequeno de publicações, cada um deles foi mais bem explorado, para se visualizar a realidade da pesquisa em GSCS nas importantes revistas selecionadas. Tal detalhamento é visto no Quadro 5.Comparando-se as revistas, aquela que mais produziu na temática foi a Revista Gestão e Produção da Universidade Federal de São Carlos (UFSCar), com 36\% dos artigos selecionados, seguida da Revista Produção da Associação Brasileira de Engenharia de Produção (ABEPRO), com 27\%. Compreende-se tal desempenho pelo foco das revistas mais voltado para a gestão da produção. A Revista Eletrônica de Administração contribuiu com dois artigos selecionados, enquanto a Revista de Administração Contemporânea (RAC) e a Revista de Administração da Universidade de São Paulo (RAUSP) contribuíram com um artigo cada uma. As demais revistas pesquisadas não apresentaram trabalhos diretamente relacionados à temática de GSCS, quando pesquisadas da maneira proposta em nossa metodologia.

Quanto à metodologia usada nas pesquisas, observa-se uma concentração em pesquisas qualitativas exploratórias, principalmente revisões teóricas e estudos de caso. Localizou-se apenas um artigo que utilizou metodologia quantitativa (AQUINO; CASTILHO JUNIOR; PIRES, 2009). Os principais resultados dos estudos analisados demonstram certas dificuldades na estruturação da logística reversa, principalmente no que diz respeito à interação dos atores na cadeia, além dos importantes desafios quanto a normas de regulação da cadeia reversa e estratégias de inovação tecnológica e gerencial. Por outro lado, as conclusões também se referem diversas vezes aos benefícios percebidos a partir da adoção de práticas de sustentabilidade e de logística reversa, como uma redução de custo no produto acabado, agregação no valor dos produtos comercializados, benefícios financeiros, redução de ataques ambientais, satisfação do cliente, benefícios logísticos e vantagem competitiva. Ademais, os estudos identificaram fatores críticos de sucesso para a gestão da sustentabilidade na cadeia de suprimentos, quais sejam a inovação tecnológica, a viabilidade econômica, as ações integradas na cadeia de suprimentos e a motivação para a sustentabilidade corporativa. No entanto, apesar dos avanços em práticas verdes, nenhum dos setores, seja público ou privado, consegue individualmente organizar-se para o alcance da efetividade operacional e ambiental desejável no cenário brasileiro.

\section{Posicionando a produção nacional frente à internacional}

A literatura internacional está mais avançada na integração das temáticas da sustentabilidade na cadeia de suprimentos em vários aspectos. Além 
da logística reversa, estuda-se remanufatura versus equipamentos novos, considerando o compromisso entre ciclo de vida decrescente e a ecoeficiência crescente nos novos equipamentos. No Brasil, o foco em estudos analisados é em logística reversa, quando ela já é considerada insuficiente (VAN HOEK; 1999, MANN et al., 2010), embora essencial, para a constituição de uma cadeia de suprimentos em ciclo fechado. lsso mostra uma grande oportunidade para pesquisa futura aos interessados no assunto. A Tabela 2 apresenta a frequência de artigos analisados por ano de publicação entre as fontes nacionais e internacionais.

0 crescimento da temática no número de publicações internacionais é observado a partir de 2001, enquanto, nacionalmente, os números não são representativos durante todo o período analisado, se comparados à produção internacional dos periódicos revisitados, embora os debates sobre as vantagens de ser verde tenham se tornado mais numerosos, e tenham progredido os estudos da GSCS. Zhu, Sarkis e Geng (2005) enfatizaram a incorporação de outras perspectivas relacionando temas socioambientais com a indústria, tais como ecossistemas industriais, ecologia industrial, a avaliação do ciclo de vida do produto, a responsabilidade extendida do produtor e o gerenciamento de produtos pós-consumo.

Nas revistas internacionais, as publicações sobre a temática datam de 1995, enquanto nas revistas nacionais, apenas a partir de 2003. Em ambas, há maior destaque para a temática em 2006, coincidindo com o desempenho das publicações internacionais, assim como no declínio das publicações nos anos seguintes. Os anos de maior publicação internacional, 2001 e 2006, representam números especiais de dois periódicos. Em 2001, International Journal of Operations and Production Management (IJOPM) publicou no seu volume 21, o número 12 sobre o tema Sustainability. Enquanto o Journal of Production and Operations Management (POM) publicou no seu volume 10 uma sequência de dois números especiais: Environmental Management and Operations Management: Introduction to Part 1 (Manufacturing and Eco-Logistics); e Environmental Management and Operations: Introduction to Part 2 (Integrating Operations and Environmental Management Systems). Em 2006, publicou outra sequência no volume 15: o número 3, sobre o tema Closed-Loop Supply Chains (Part 1); e o número 4: Closed-Loop Supply Chains (Part 2).

Os resultados mostram que 50\% dos trabalhos envolvendo as principais palavras-chave nos periódicos internacionais que definem a temática da GSCS apareceram a partir de 2005, o que indica sua necessidade de maturação, sugerindo um campo com grande potencial para estudos futuros. No caso das publicações das revistas nacionais, todos os artigos referentes à GSCS são dos anos mais recentes, o que mostra uma necessidade ainda maior de estudos na área no Brasil para seu desenvolvimento, expansão, maturação e consolidação. Ao analisarem-se as palavras-chave mais citadas (Tabela 3), observa-se que tanto nos artigos nacionais quanto nos internacionais selecionados, a maior parte trata do conceito de logística reversa (91\% dos nacionais e 46\% dos internacionais).

De maneira geral, enquanto a produção nacional analisada abordou apenas três (logística verde, logística reversa, cadeia reversa) dos nove conceitos pesquisados por palavras-chave, a produção internacional selecionada abrangeu seus estudos em oito delas, demonstrando maior maturidade e expansão das pesquisas no tema em comparação à publicação nacional que ainda é pontual e escassa, como pode ser evidenciado na Tabela 4.

Tabela 2. Frequência de artigos por ano de publicação. Fonte: Dados da pesquisa.

\begin{tabular}{ccc}
\hline Ano & Internacional & Nacional \\
\hline 1995 & 1 & 0 \\
1996 & 2 & 0 \\
1997 & 1 & 0 \\
1998 & 1 & 0 \\
1999 & 1 & 0 \\
2000 & 0 & 0 \\
2001 & 6 & 0 \\
2002 & 4 & 0 \\
2003 & 2 & 1 \\
2004 & 5 & 0 \\
2005 & 5 & 0 \\
2006 & 18 & 6 \\
2007 & 5 & 2 \\
2008 & 4 & 1 \\
2009 & 1 & 1 \\
\hline
\end{tabular}

Tabela 3. Frequência de artigos por palavra-chave. Fonte: Dados da pesquisa.

\begin{tabular}{lcc}
\hline & Internacional & Nacional \\
\hline Produto verde & 3 & 0 \\
Operações verde & 0 & 0 \\
Compra verde/sustentável & 2 & 0 \\
Logística verde/ sustentável & 2 & 1 \\
Logística reversa & 26 & 10 \\
Cadeia reversa & 6 & 3 \\
Cadeia de suprimentos em circuito & 16 & 0 \\
fechado & 7 & 0 \\
Cadeia de suprimentos verde & 1 & 0 \\
Cadeia de suprimentos sustentável & & \\
\hline
\end{tabular}


Entretanto, embora nenhum artigo nacional tenha focado na gestão da sustentabilidade na cadeia de suprimentos, apenas um artigo internacional abordou o termo sustainable supply chain (LINTON; KLASSEN; JAYARAMAN, 2007), denotando que, mesmo o mainstream internacional da área de operações ainda não incorporou à temática GSCS. Esta constatação foi corroborada pela busca estendida do termo no portal EBSCO, em que apareceram 77 artigos. Apesar da primeira menção ao termo datar de 2003, $86 \%$ dos resultados concentram-se a partir de 2007. 0 mesmo resultado se repete pesquisando-se o termo green supply chain presente em $64 \%$ das publicações, a partir do mesmo ano (Tabela 5).

Considerando-se a prevalência de estudos abordando o conceito de logística reversa, é preciso considerar que, apesar de alguns avanços iniciais, esta literatura tem fornecido uma abordagem limitada para classificar o relacionamento entre a organização e seu meio ambiente natural. Falha, portanto, em endereçar as condições e fatores que devem ser observados para uma empresa estruturar-se em direção à sustentabilidade (HANDFIELD et al., 1997). Iniciativas de pesquisa são necessárias para cobrir esta lacuna. Especificamente, a pesquisa deve se mover da logística reversa para o desenvolvimento de gestão da sustentabilidade em cadeias de suprimentos. Assim, a inclusão da abordagem da cadeia de suprimentos representa uma perspectiva sistêmica para atingir as iniciativas mais conectadas com a perspectiva da sustentabilidade (VAN HOEK, 1999), conforme esquema da Figura 2.

Tabela 4. Frequência absoluta e relativa de artigos por palavra-chave.

\begin{tabular}{|c|c|c|c|c|c|c|}
\hline \multicolumn{3}{|c|}{ Temática } & \multirow{2}{*}{$\begin{array}{c}\begin{array}{c}\text { Total } \\
\text { Nacional }\end{array} \\
0\end{array}$} & \multirow{2}{*}{$\begin{array}{c}\text { Total \% } \\
0 \\
\end{array}$} & \multirow{2}{*}{$\begin{array}{c}\begin{array}{c}\text { Total } \\
\text { Internacional }\end{array} \\
3 \\
\end{array}$} & \multirow{2}{*}{$\begin{array}{c}\text { Total \% } \\
5 \\
\end{array}$} \\
\hline \multirow{9}{*}{$\begin{array}{c}\text { Gestão da } \\
\text { Sustentabilidade } \\
\text { na cadeia de } \\
\text { suprimentos (GSCS) }\end{array}$} & Design verde & produto verde & & & & \\
\hline & \multirow{7}{*}{$\begin{array}{l}\text { Gestão da cadeia de } \\
\text { suprimentos verde } \\
\text { (GCSV) }\end{array}$} & operações verdes & 0 & 0 & 0 & 0 \\
\hline & & compra verde/sustentável & 0 & 0 & 2 & 4 \\
\hline & & logistica verde/sustentável & 1 & 9 & 2 & 4 \\
\hline & & logística reversa & 10 & 91 & 26 & 46 \\
\hline & & cadeia reversa & 3 & 27 & 6 & 11 \\
\hline & & cadeia de suprimentos em circuito fechado & 0 & 0 & 16 & 29 \\
\hline & & cadeia de suprimentos verde & 0 & 0 & 7 & 13 \\
\hline & \multicolumn{2}{|c|}{ Cadeia de suprimentos sustentáveis } & 0 & 0 & 1 & 2 \\
\hline Total & & & 11 & & 56 & \\
\hline
\end{tabular}

Fonte: dados da pesquisa.

Tabela 5. Frequência de artigos encontrados na busca estendida.

\begin{tabular}{|c|c|c|c|c|c|c|c|c|c|c|c|c|c|}
\hline \multirow{2}{*}{ Conceito } & \multicolumn{13}{|l|}{ ano } \\
\hline & 1998 & 1999 & 2000 & 2001 & 2002 & 2003 & 2004 & 2005 & 2006 & 2007 & 2008 & 2009 & total \\
\hline Sustainable supply chain & 0 & 0 & 0 & 0 & 0 & 1 & 1 & 1 & 1 & 3 & 9 & 14 & 30 \\
\hline Green supply chain & 2 & 0 & 0 & 3 & 0 & 2 & 3 & 4 & 3 & 8 & 14 & 8 & 47 \\
\hline Total & 2 & 0 & 0 & 3 & 0 & 3 & 4 & 5 & 4 & 11 & 23 & 22 & 77 \\
\hline
\end{tabular}

Fonte: dados da pesquisa.

\begin{tabular}{|l|l|}
\hline \multicolumn{2}{|c|}{ Logística reversa } \\
Reativa, cumpre regulação
\end{tabular}

Figura 2. Da Logística Reversa para Gestão da Sustentabilidade em Cadeias de Suprimentos. Fonte: Van Hoek (1999, p. 132). 
Em conformidade com a proposta de Van Hoek (1999), considera-se neste artigo que a Logística Reversa sozinha não é suficiente para uma visão integrada da cadeia. E assim, a abordagem da sustentabilidade ao longo da cadeia de suprimentos é mais relevante para entender as relações das empresas, do meio ambiente e das questões sociais. A incorporação da questão social no âmbito das cadeias não se limita a reações de causa e efeito, envolvendo a participação de apenas uma empresa, pois quando associadas à estratégia global do negócio são capazes de desencadear inovações que reduzem os custos totais de produção e aumentam o valor agregado perante o mercado (ALIGLERI; ALIGLERI; KRUGLIANSKAS, 2009).

\section{Considerações finais}

0 modelo produtivo da gestão empresarial tradicional enxerga a natureza como uma fonte inesgotável de recursos à disposição do ser humano. No entanto, esse paradigma está sofrendo alterações a cada dia, o ciclo de renovação e oferta da natureza não está conseguindo atingir a mesma velocidade que a demanda. Entretanto há que se destacar que há pouco mais de uma década, o tema sustentabilidade era visto à margem do mundo dos negócios. Era como se fossem iniciativas compensatórias apoiadas em projetos aqui e acolá (GONÇALVES-DIAS; MACIEL; SOARES, 2009).

No Brasil, o foco dos estudos se concentra em logística reversa havendo necessidade de estudar, a exemplo de pesquisas internacionais, outros aspectos da GSCS, considerando a interdisciplinaridade.

GSCS pode reduzir o impacto ambiental da atividade industrial sem sacrificar qualidade, custo, confiabilidade, desempenho ou eficiência do uso de energia. Entretanto, as dimensões que balizam a sustentabilidade influenciam todas as organizações constituintes de uma cadeia produtiva, e não somente uma organização ou empresa focal.

A análise da literatura mostra que GSCS é um campo relativamente "jovem" com exponencial crescimento do interesse de pesquisadores nos últimos três anos. A pesquisa em GSCS tem sido pontual, fragmentada e parcial. A maioria dos estudos tem sido feitos com amostras limitadas, buscando a generalização dos resultados. Há ainda negligência quanto aos aspectos sociais na pesquisa sobre GSCS (CARTER; JENNINGS, 2004; VURRO; RUSSO; PERRINI, 2009). Tais evidências são também obstáculos para a consolidação da literatura e das práticas de sustentabilidade em cadeia de suprimentos.

Na verdade, GSCS envolve uma mudança de paradigma, em que a questão da sustentabilidade deixa de ser vista como fonte de custos, passando a representar uma potencial fonte de vantagem competitiva para as empresas envolvidas numa cadeia, conforme proposição da hipótese de Porter. A recente inclusão da noção de sustentabilidade na gestão e nas práticas da cadeia de suprimentos tem fornecido oportunidades para rever conceitos, processos, operação e materiais por diferentes perspectivas. As mudanças geradas representam introdução de novas práticas, assim como mudança de práticas existentes, para criar um novo sistema de produção-consumo (LINTON; KLASSEN; JAYARAMAN, 2007).

Ademais, há que se considerar o papel estratégico do nosso país frente a impactos socioambientais globais que podem ser minimizados com a gestão da sustentabilidade em cadeias produtivas como as da soja, carne, cana-de-açúcar, madeira entre outras. Em outras palavras, é preciso dar ênfase à realidade do país, ressaltar inovações genuinamente brasileiras, ofertar pesquisas sobre alternativas em termos de uso de materiais, conservação energética, equacionamento dos desmatamentos e sobre iniciativas práticas ainda não sistematizadas pela academia. Incorporar a preocupação do papel social e ambiental para criar valor na cadeia de suprimentos revela-se como um grande desafio para os gestores do século XXI.

Como estudos futuros, sugerem-se as seguintes áreas chave: (i) construção, validação e refinamento teórico, para avanços do campo; (ii) abordagens teóricas e práticas integradas, colaborativas e muldisciplinares para mostrar a interação entre motivações estruturais, estratégicas e institucionais da cadeia (MATOS; HALL, 2007; MELNYK et al., 2009); (iii) estudos reflexivos, expandindo os métodos de investigação, com abordagem metodológica menos positivista; (iv) formulação de um sistema de mensurarão de desempenho para avaliar as iniciativas socioambientais; (v) explorar as interdependências entre a noção de sustentabilidade e gestão de cadeias, numa tentativa de identificar articulações entre aspectos teóricos e soluções operacionais satisfatórias.

\section{Referências}

ADLMAIER, D.; SELLITTO, M. A. Embalagens retornáveis para transporte de bens manufaturados: um estudo de caso em logística reversa. Produção, v. 17, n. 2, p. 395-406, 2007.

ALIGLERI, L.; ALIGLERI, L. A.; KRUGLIANSKAS, 1. Gestão Socioambiental: Responsabilidade e Sustentabilidade do Negócio. São Paulo: Atlas, p. 29-50, 2009.

AQUINO, I. F.; CASTILHO JUNIOR, A. B.; PIRES, T. S. L. A organização em rede dos catadores de materiais recicláveis na cadeia produtiva reversa de pós-consumo da região da grande Florianópolis: uma alternativa de agregação de valor. Gestão e Produção, v. 16, n. 1, p. 15-24, 2009 http://dx.doi.org/10.1590/S0104-530X2009000100003 
ARAS, N.; BOYACl, T.; VERTER, V. The effect of categorizing returned products in remanufacturing. Fontainebleau, 2006. Working paper, INSEAD, 2006/58/TOM/MKT.

ARONSSON, H.; BRODIN, M. H. The environmental impact of changing logistics structures. International Journal of Logistics Management, v. 17, n. 3, p. 394-415, 2006. http://dx.doi.org/10.1108/09574090610717545

ATASU, A.; CETINKAYA, S. Lot Sizing for Optimal Collection and Use of Remanufacturable Returns over a Finite Life-Cycle. Production and Operations Management, v. 15, n. 4 , p. 473-488, 2006. http://dx.doi. org/10.1111/j.1937-5956.2006.tb00157.x

ATASU, A.; GUIDE, V.; VAN WASSENHOVE, L. N. Product Reuse Economics in Closed-Loop Supply Chain Research. Production and Operations Management, v. 17, n. 5, p. 483-496, 2008. http://dx.doi.org/10.3401/ poms. 1080.0051

BAKAL, 1. S.; AKCALl, E. Effects of Random Yield in Remanufacturing with Price-Sensitive Supply and Demand. Production and Operations Management, v. 15, n. 3, p. 407-420, 2006. http://dx.doi. org/10.1111/j.1937-5956.2006.tb00254.x

BARNES JUNIOR, J. H. Recycling: A Problem in Reverse Logistics. Journal of Macromarketing, v. 2, no. 2, 1982. http://dx.doi.org/10.1177/027614678200200204

BARTLEY, T. Institutional emergence in an era of globalization: The rise of transnational private regulation of labor and environmental conditions. American Journal of Sociology, v. 113 n. 2, p. 297-351, 2007. http://dx.doi. org/10.1086/518871

BLOEMHOF-RUWAARD, J. M. et al. Interactions between operations research and environmental management. European Journal of Operational Research, v. 85, n. 2, p. 229-243, 1995. http://dx.doi. org/10.1016/0377-2217(94)00294-M

CAINCROSS, F. Costing the earth: the challenge for governments, the opportunities for business. Harvard Business School Press, 1992. 341 p.

CARTER, C. R.; ELLRAM, L. M. Reverse Logistics: A Review of the Literature and Framework for Future Investigation. Journal of Business Logistics, v. 19, n. 1, p. 85-102, 1998.

CARTER, C. R.; JENNINGS, M. M. The Role Of Purchasing In Corporate Social Responsibility: A Structural Equation Analysis. Journal of Business Logistics, v. 25, n. 1, p. 145-186, 2004. http://dx.doi. org/10.1002/j.2158-1592.2004.tb00173.x

CHAKRABORTY, S. Concise Chronological Road Map of Evolving Green Supply Chain Management Concepts: A Review. The IUP Journal 12 of Supply Chain Management, v. 7, n. 4, 2010.

CHANDRASHEKAR, A.; DOUGLESS, T. Commodity Indexed Surplus Asset Disposal in the Reverse Logistics Process. International Journal of Logistics Management, v. 7, n. 2, p. 59-68, 1996. http://dx.doi. org/10.1108/09574099610805520

CHAVES, G. L. D.; BATALHA, M. O. Os consumidores valorizam a coleta de embalagens recicláveis? Um estudo de caso da logística reversa em uma rede de hipermercados. Gestão e Produção, v. 13, n. 3, p. 423-434, 2006. http:// dx.doi.org/10.1590/S0104-530X2006000300006

CHEN, C. Design for the Environment: A Quality-Based Model for Green Product Development. Management Science, v. 47, n. 2, p. 250-263, 2001. http://dx.doi.org/10.1287/ mnsc.47.2.250.9841

CLENDENIN,J.A.Closing theSupplyChain Loop:Reengineering the Returns Channel Pocess. International Journal of Logistics Management, v. 8, n. 1, p. 75-85, 1997. http:// dx.doi.org/10.1108/09574099710805600

CONROY, M. E. Branded! How the Certification Revolution" is Transforming Global Corporations. Gabriola lsland: New Society Publishers, 2007.

CORBETT, C. J.; KLEINDORFER, P. R. Introduction to the special issue on environmental management and operations. Production and Operations Management, v. 10, n. 2, p. 107-111, 2001. http://dx.doi. $\operatorname{org} / 10.1111 / \mathrm{j} .1937-5956.2001 . t b 00072 . x$

CORBETT, C. J. Sustainability as driver of operational excellence in supply chains (key note speaker). ln: JORNADA DE LOGÍSTICA E SUPPLY CHAIN MANAGEMENT, 1., 2009, São Paulo. Anais... São Paulo: Escola Politécnica da Universidade de São Paulo, 2009.

DAUGHERTY, P. J.; AUTRY, C. W.; ElLINGER, A. E. Reverse Logistics: The Relationship Between Resource Commitment and Program Performance. Journal of Business Logistics, v. 22, n. 1, 2001. http://dx.doi. org/10.1002/j.2158-1592.2001.tb00162.x

DAUGHERTY, P. J.; MYERS, M. B.; RICHEY, R. G. Information Support for Reverse Logistics: The influence of relationship commitment. Journal of Business Logistics, v. 23, n. 1, 2002. http://dx.doi.org/10.1002/j.2158-1592.2002. tb00017.x

DAUGHERTY, P. J. et al. Reverse Logistics in the Automobile Aftermarket Industry. International Journal of Logistics Management, v. 14, n. 1, p. 49-62, 2003. http://dx.doi. org/10.1108/09574090310806530

DEBO, L. G.; TOKTAY, L. B.; VAN WASSENHOVE, L. N. V. Joint Life-Cycle Dynamics of New and Remanufactured Products. Production and Operations Management, v. 15, n. 4, p. 498-513, 2006. http://dx.doi. $\operatorname{org} / 10.1111 / j .1937-5956.2006 . t b 00159 . x$

DECROIX, G. A.; ZIPKIN, P. H. Inventory Management for an Assembly System with Product or Component Returns. Management Science, v. 51, n. 8, p. 1250-1265, 2005. http://dx.doi.org/10.1287/mnsc. 1050.0394

FLEISCHMANN, M. et al. The impact of product recovery on logistics network design. Production and Operations Management, v. 10, n. 2, p. 156-173, 2001. http:// dx.doi.org/10.1111/j.1937-5956.2001.tb00076.x

FRENCH, M. L.; LAFORGE, R. L. Closed-loop supply chains in process industries: An empirical study of producer re-use issues. Journal of Operations Management, v. 24, p. 271-286, 2006. http://dx.doi.org/10.1016/j. jom.2004.07.012

GEORGIADIS, P.; VLACHOS, D.; TAGARAS, G. The Impact of Product Lifecycle on Capacity Planning of Closed-Loop Supply Chains with Remanufacturing. Production and Operations Management, v. 15, n. 4, p. 514-527, 2006. http://dx.doi.org/10.1111/j.1937-5956.2006.tb00160.x

GIACOBO, F.; ESTRADA, R. J. S.; SÉRGIO, P. Logística Reversa: A Satisfação do Cliente no Pós-Venda. Revista Eletrônica de Administração, v. 9, n. 5, 2003.

GINTER, P. M.; STARLING, J. M. Reverse distribution channels for recycling. California Management Review, v. 20, n. 3, p. 72-81, 1978. 
GlOVANNINI, F.; KRUGLIANSKAS, 1. Fatores Críticos de Sucesso para a Criação de um Processo Inovador Sustentável de Reciclagem: um Estudo de Caso. Revista de Administração Contemporânea, v. 12, n. 4, 2008.

GONÇALVES-DIAS, S. L. F. Há vida após a morte: um (re) pensar estratégico para o fim da vida das embalagens. Gestão e Produção, v. 13, n. 3, p. 463-474, 2006. http:// dx.doi.org/10.1590/S0104-530X2006000300009

GONCALVES-DIAS, S. L. F.; TEODÓS1O, T. A. S. S. Estrutura da cadeia reversa: "caminhos" e "descaminhos" da embalagem PET. Produção, v. 16, n. 3, p. 429-441, 2006. http://dx.doi.org/10.1590/S0103-65132006000300006

GONÇALVES-DIAS, S. L. F.; MACIEL, F. S.; SOARES, J. D. A. Desafios para gestão da sustentabilidade em cadeias de suprimentos: uma análise exploratória na cadeia da carne bovina brasileira. In: CONFERENNCIA INTERNACIONAL DE INOVAÇÃO E GESTÃO - ICIM, 6., 2009, São Paulo. Anais... São Paulo: PUC-SP, Núcleo de Estudos do Futuro, 2009.

GONÇALVES, M. E.; MARINS, F. A. S. Logística Reversa numa Empresa de Laminação de Vidros: Um Estudo de Caso. Revista Gestão e Produção, v. 13, n. 3, p. 397-410, 2006.

GUARNIERI, P. et al. WMS -Warehouse Management System: adaptação proposta para o gerenciamento da logística reversa. Produção, v. 16, n. 1, p. 126-139, 2006. http:// dx.doi.org/10.1590/S0103-65132006000100011

GUIDE, V. D. R. et al. Time Value of Commercial Product Returns. Management Science, v. 52, n. 8, p. 1200-1214, 2006. http://dx.doi.org/10.1287/ mnsc. 1060.0522

GUIDE, V. D. R.; JAYARAMAN, V.; LINTON, J. D. Building contingency planning for closed-loop supply chains with product recovery. Journal of Operations Management, v. 21 , p. 259-279, 2003. http://dx.doi.org/10.1016/ S0272-6963(02)00110-9

GUIDE, V. D. R.; VAN WASSENHOVE, L. N. Managing product returns for remanufacturing. Production and Operations Management, v. 10, p. 142-155, 2001. http://dx.doi. org/10.1111/j.1937-5956.2001.tb00075.x

GUIDE, V. D. R.; VAN WASSENHOVE, L. N. Closed-Loop Supply Chains: An Introduction to the Feature Issue (Part 1). Production and Operations Management, v. 15, n. 3, p. 345-350, 2006a. http://dx.doi. $\operatorname{org} / 10.1111 /$ j.1937-5956.2006.tb00249.x

GUIDE, V. D. R.; VAN WASSENHOVE, L. N. Closed-Loop Supply Chains: An Introduction to the Feature Issue (Part 2). Production and Operations Management, v. 15, n. 4, p. 471-472, 2006b. http://dx.doi. org/10.1111/j.1937-5956.2006.tb00156.x

HANAFI, J.; KARA, S.; KAEBERNICK, H. Reverse logistics strategies for end-of-life products. International Journal of Logistics Management, v. 19, n. 3, p. 367-388, 2008. http://dx.doi.org/10.1108/09574090810919206

HANDFIELD, R. B. et al. Green value chain practices in the furniture industry. Journal of Operations Management, v. 15, p. 293-315, 1997. http://dx.doi.org/10.1016/ S0272-6963(97)00004-1

JAYARAMAN, V.; PATTERSON, R. A.; ROLLAND, E. The design of reverse distribution networks: models and solution procedures. European Journal of Operational Research, v. 150, p. 128-149, 2003. http://dx.doi.org/10.1016/ S0377-2217(02)00497-6
KETZENBERG, M. E.; LAAN, E. V. D.; TEUNTER, R. H. Value of Information in Closed Loop Supply Chains. Production and Operations Management, v. 15, n. 3, p. 393-406, 2006 http://dx.doi.org/10.1111/j.1937-5956.2006.tb00253.x

KITZMANN, D.; ASMUS, M. Gestão ambiental portuária: desafios e possibilidades. Revista de Administração Pública - RAP, v. 40, n. 6, 2006.

KLEINDORFER, P. R.; SINGHAL, K.; VAN WASSENHOVE, L. N. Sustainable Operations Management. Production and Operations Management, v. 14, n. 4, p. 482-492, 2005. http://dx.doi.org/10.1111/j.1937-5956.2005.tb00235.x

KOCABASOGLU, C.; PRAHINSKI, C.; KLASSEN, R. D. linking forward and reverse supply chain investments: The role of business uncertainty. Journal of Operations Management, v. 25, n. 6, p. 1141, 2007. http://dx.doi. org/10.1016/j.jom.2007.01.015

KOPICKI, R.; BERG, M.; LEGG, L. L. Reuse and recycling: reverse logistics opportunities. 1llinois: Oak Brook, Council of Logistics Management, 1993.

KULP, S. C.; LEE, H. L.; OFEK, E. Manufacturer Benefits from Information Integration with Retail Customers. Management Science, v. 50, n. 4, p. 431-444, 2004. http://dx.doi.org/10.1287/mnsc. 1030.0182

LAMBERT, D.; STOCK, J. Strategic physical distribution management. Homewood: Irwin, 1981.

LEE, S.; KLASSEN, R. Drivers and Enablers That Foster Environmental Management Capabilities in Small- and Medium-Sized Suppliers in Supply Chains. Production and Operations Management, v. 17, n. 6, p. 573-586, 2008. http://dx.doi.org/10.3401/poms.1080.0063

LINTON, J. D.; KLASSEN, K.; JAYARAMAN, V. Sustainable supply chains: An introduction. Journal of Operations Management, v. 25, p. 1075-1082, 2007. http://dx.doi. $\operatorname{org} / 10.1016 /$ j.jom.2007.01.012

MAJUMDER, P.; GROENEVELT, H. Competition in remanufacturing. Production and Operations Management, v. 10, n. 2, p. 125-141, 2001. http:// dx.doi.org/10.1111/j.1937-5956.2001.tb00074.x

MANN, H. et al. Drivers of Sustainable Supply Chain Management. The IUP Journal of Operations Management, v. 9, n. 4, 2010.

MATOS, S.; HALL, J. Integrating sustainable development in the supply chain: The case of life cycle assessment in oil and gas and agricultural biotechnology. Journal of Operations Management, v. 25, p. 1083-1102, 2007. http://dx.doi.org/10.1016/j.jom.2007.01.013

McDONOUGH, W.; BRAUNGART, M. Cradle to Cradle: Remaking the way we make things. New York: North Point Press, 2002.

MELNYK, S. et al. Mapping the future of supply chain management: a Delphi study. International Journal of Production Research, v. 47, n. 16, 2009. 4629-4653. http://dx.doi.org/10.1080/00207540802014700

MIN, H.; GALLE, W. P. Green purchasing practices of US firms. International Journal of Operations \& Production Management, v. 21, n. 9-10, p. 1222-1238, 2001. http:// dx.doi.org/10.1108/EUM0000000005923

MUKHOPADHYAY, S. K.; SETOPUTRO, R. Optimal return policy and modular design for build-to-order products. Journal of Operations Management, v. 23, p. 496-506, 2005. http://dx.doi.org/10.1016/j.jom.2004.10.012 
MURPHY, P. R.; POIST, R. F.; BRAUNSCHWEIG, C. D. Green Logistics: comparative views of environmental Progressives, moderates, and conservatives. Journal of Business Logistics, v. 17, n. 1. 1996.

PEDROSO, M. C.; ZWICKER, R. Sustentabilidade na cadeia reversa de suprimentos: um estudo de caso do Projeto Plasma. Revista de Administração da USP, v. 42, n. 4, 2007.

PILKINGTON, A.; FITZGERALD, R. Operations Management themes, concepts and relationships: a forward retrospective of IJOPM. International Journal of Operations \& Production Management, v. 26, n. 11, p. $1255-1275,2006$. http://dx.doi. org/10.1108/01443570610705854

PORTER, M. E.; VAN DER LINDE, C.. Green and Competitive: Ending the stalemate. Harvard Business Review, v. 73, n. 5 , p. $120-134,1995$.

QUAK, H. J.; KOSTER, M. B. M. Exploring retailers' sensitivity to local sustainability policies. Journal of Operations Management, v. 25, p. 1103-1122, 2007. http://dx.doi. org/10.1016/j.jom.2007.01.020

RAJAMANI, D.; GEISMAR, H. N.; SRISKANDARAJAH, C. A Framework to Analyze Cash Supply Chains. Production and Operations Management, v. 15, n. 4, p. 544-552, 2006. http://dx.doi.org/10.1111/j.1937-5956.2006.tb00162.x

RA0, P. Greening production: a South-East Asian experience. International Journal of Operations \& Production Management, v. 24, n. 3, p. 289-320, 2004. http:// dx.doi.org/10.1108/01443570410519042

RAO, P. Greening the supply chain: a new initiative in South East Asia. International Journal of Operations \& Production Management, v. 22, n. 6, p. 632-655, 2002. http://dx.doi.org/10.1108/01443570210427668

RAO, P.; HOLT, D. Do green supply chains lead to competitiveness and economic performance? International Journal of Operations \& Production Management, v. 25, n. 9, 2005. http://dx.doi. org/10.1108/01443570510613956

REZENDE, A. J.; DALMÁCIO F. Z.; SLOMSKI, V. Impacto Econômico Financeiro da Logística Reversa: Uma Aplicação no Segmento de Distribuição de Matérias-Primas Farmacêuticas. Revista Eletrônica de Administração, v. 12, n. 6, 2006.

RICHEY, R. G. et al. Reverse Logistics: The impact of timing and resources. Journal of Business Logistics, v. 25, n. 2, 2004. http://dx.doi.org/10.1002/j.2158-1592.2004. tb00188.x

ROGERS, D. S.; TIBBEN-LEMBKE, R. An Examination of Reverse Logistics Practices. Journal of Business Logistics, v. 22, n. 2, 2001. http://dx.doi.org/10.1002/j.2158-1592.2001. tb00007.x

ROGERS, D. S. et al. The Return Management Process. International Journal of Logistics Management, v. 13, n. 2, p. 1-18, 2002. http://dx.doi. org/10.1108/09574090210806397

ROSENBURG, C. 0 ambientalista que convence o capital. Revista Exame, 30 ago. 2006. Disponível em: <http:// planetasustentavel.abril.com.br/noticia/atitude/ conteudo_225819.shtml>. Acesso em: 06 mar. 2007.

SACHS, 1. Rumo à ecossocioeconomia: teoria e prática do desenvolvimento. São Paulo: Cortez, 2007.

SAVASKAN, R. C.; BHATTACHARYA, S.; VAN WASSENHOVE, L. N. Closed-Loop Supply Chain Models with Product
Remanufacturing. Management Science, v. 50, n. 2, p. 239-252, 2004. http://dx.doi.org/10.1287/ mnsc. 1030.0186

SAVASKAN, S. V.; VAN WASSENHOVE, L. N. Reverse Channel Design: The Case of Competing Retailers. Management Science, v. 52, n. 1, p. 1-14, 2006. http://dx.doi. org/10.1287/mnsc. 1050.0454

SEURING, S.; MULLER, M. From a Literature Review to a Conceptual Framework for Sustainable Supply Chain Management. Journal of Cleaner Production, v. 16, p. 1699-1710, 2008. http://dx.doi.org/10.1016/j. jclepro.2008.04.020

SIMPSON, D.; POWER, D.; SAMSON, D. Greening the automotive supply chain: a relationship perspective. International Journal of Operations \& Production Management, v. 27, n. 1, 2007. http://dx.doi. org/10.1108/01443570710714529

SNIR, E. M. S. Liability as a catalyst for product stewardship. Production and Operations Management, v. 10, n. 2, p. 190-206, 2001. http://dx.doi. org/10.1111/j.1937-5956.2001.tb00078.x

SOUZA, G. C.; KETZENBERG, M. E.; GUIDE, V. D. R. Capacitated Remanufacturing With service level constraints. Poms Series in Technology and Operations Management, v. 11, 2002.

SRIVASTAVA, S. K. Green Supply Chain Management: A State-of-the-Art Literature Review. International Journal of Management Reviews, v. 9, n. 1, p. 53-80, 2007. http://dx.doi.org/10.1111/j.1468-2370.2007.00202.x

STOCK, J. R. Reverse Logistics. Illinois: Oak Brook, Council of Logistics Management, 1992.

STOCK, J.; MULKl, J. Product returns processing: an examination of practices of manufacturers, wholesalers/distributors, and retailers. Journal of Business Logistics, v. 30, n. 1, 2009. http://dx.doi. org/10.1002/j.2158-1592.2009.tb00098.x

SVENSSON, G. Aspects of sustainable supply chain management (SSCM): conceptual framework and empirical example. Supply Chain Management: An International Journal, v. 12, n. 4, p. 262-266, 2007. http://dx.doi.org/10.1108/13598540710759781

TAN, A. W. K.; KUMAR, A. A decision-making model for reverse logistics in the computer industry. The International Journal of Logistics Management, v. $17, \quad$ n. 3, p. 331-354, 2006. http://dx.doi. org/10.1108/09574090610717518

TANG, 0.; TEUNTER, R. Economic Lot Scheduling Problem with Returns. Production and Operations Management, v. $15, \quad$ n. 4, p. 488-497, 2006. http://dx.doi. org/10.1111/j.1937-5956.2006.tb00158.x

THIERRY, M. et al. Strategic lssues in Product Recovery Management. California Management Review, v. 37, n. 2, 1995.

VACHON, S.; KLASSEN, R. D. Extending green practices across the supply chain The impact of upstream and downstream integration. International Journal of Operations \& Production Management, v. 26, n. 7, p. 795-821, 2006. http://dx.doi.org/10.1108/01443570610672248

VAN HOEK, R. From reversed logistics to green supply chains. Supply Chain Management, v. 4, n. 3, p. 129-134, 1999. http://dx.doi.org/10.1108/13598549910279576

VERMEULEN, W. J. V.; SEURING, S. Sustainability Through the Market - the Impacts of Sustainable Supply Chain 
Management: Introduction. Sustainable Development, v. 17, p. 269-273, 2009. http://dx.doi.org/10.1002/sd.422

VORASAYAN, J.; RYAN, S. M. Optimal Price and Quantity of Refurbished Products. Production and Operations Management, v. 15, n. 3, p. 369-383, 2006. http:// dx.doi.org/10.1111/j.1937-5956.2006.tb00251.x

VURRO, C.; RUSSO, A.; PERRINI, F. Shaping Sustainable Value Chains: Network Determinants of Supply Chain Governance Models. Journal of Business Ethics, v. 90, p. 607-621, 2009. http://dx.doi.org/10.1007/s10551-010-0595-x

WEBSTER, S.; MITRA, S. Competitive strategy in remanufacturing and the impact of take-back laws. Journal of Operations Management, v. 25, p. 1123-1140, 2007. http://dx.doi.org/10.1016/j. jom.2007.01.014

WIKNER, J.; TANG, 0. A structural framework for closedloop supply chains. International Journal of Logistics Management, v. 19 n. 3, p. 344-366, 2008.http://dx.doi. org/10.1108/09574090810919198

ZHANG, H. C. et al. Environmentally conscious design and manufacturing: a state-of-the-art survey. Journal of
Manufacturing Systems, v. 16, p. 352-371, 1997. http:// dx.doi.org/10.1016/S0278-6125(97)88465-8

ZHU, Q.; GENG, Y. Integrating Environmental Issues Into Supplier Selection and Management. Greener Management International, n. 35, p. 27, 2001.

ZHU, Q.; SARKIS, J. Relationships between operational practices and performance among early adopters of green supply chain management practices in Chinese manufacturing enterprises. Journal of Operations Management, v. 22, p. 265-289, 2004. http://dx.doi. $\operatorname{org} / 10.1016 /$ j.jom.2004.01.005

ZHU, Q.; SARKIS, J.; GENG, Y. Green supply chain management in China: pressures, practices and performance. International Journal of Operations \& Production Management, v. 25, n. 5, p. 449-468, 2005. http://dx.doi.org/10.1108/01443570510593148

ZIKMUND, W. G.; STANTON, W. T. Recycling solid wastes: a channel of distributions Problem. Journal of Marketing, v. 3, n. 35, p. 34-39, 1971. http://dx.doi. $\operatorname{org} / 10.2307 / 1249787$

\title{
Sustainability in supply chains: a comparative perspective in domestic and international journals
}

\begin{abstract}
This article provides a reference frame of concepts in Supply Chain Sustainability Management (SCSM), helping future research in the attempt to integrate intra and interorganizational choices based on the aspects of sustainability in supply chains. It is a theoretical study and the methodological procedure adopted was the desk research, organized in two steps. Firstly, the theme study was analyzed in six international journals, totaling 53 articles between 1954 and 2009. This step generated an evolution of the area, helping to pinpoint trends. Secondly, six domestic journals were reviewed and 11 articles were selected between 1961 and 2009, resulting in an overview of the theme in the Brazilian academic context. The concept of GSCS appeared only in 2007, which shows the relevance of the topic; although this is a gathering of topics previously studied separately.
\end{abstract}

\section{Keywords}

Sustainability. Supply chain. Sustainable supply chain. Reverse logistics. Desk research. 